\title{
Identification and Functional Characterization of an Effector Secreted by Cronartium ribicola
}

\author{
Zhenguo Ma, Jun-Jun Liu, ${ }^{\dagger}$ and Arezoo Zamany \\ Canadian Forest Service, Natural Resources Canada, 506 West Burnside Road, Victoria, BC V8Z 1M5, Canada \\ Accepted for publication 15 January 2019.
}

\begin{abstract}
Cri-9402 was identified as a protein effector from Cronartium ribicola, based on the effect of its expression on growth of Pseudomonas syringae Psm ES4326 introduced into transiently transformed tobacco leaves and stably transformed Arabidopsis seedlings. In tobacco leaves transiently expressing its coding sequence, growth of $P$. syringae Psm ES4326 was inhibited. Expression of pathogenesis-related $(P R)$ protein 2 (PR2), PR4a, endochitinase B, hypersensitive-related 201 (HSR201), $H S R 203 \mathrm{~J}$, and proteinase inhibitor 1 was upregulated but expression of PR1, coronatine insensitive 1 , and abscisic acid 1 was significantly suppressed. In transformed Arabidopsis seedlings, the effector stimulated growth of $P$. syringae Psm ES4326; significantly

suppressed expression of $P R 1, P R 2$, nonexpresser of pathogenesisrelated genes 1 (NPR1), NPR3, NPR4, phytoalexin deficient 4, and salicylic acid induction deficient 2; and enhanced expression of plant defensin 1.2 (PDF 1.2). The above results showed that the majority of responses to this effector in tobacco leaves were converse to those in transformed Arabidopsis. We could conclude that Cri-9402 promoted disease resistance in tobacco leaves and disease susceptibility in Arabidopsis seedlings. Its transcript was mainly expressed in aeciospores of $C$. ribicola and was probably involved in production or germination of aeciospores, and it was an effector potentially functioning in white pine-blister rust interactions.
\end{abstract}

White pine blister rust (WPBR) disease, caused by the nonnative fungal pathogen Cronartium ribicola, is a lethal threat to native five-needle pine trees and their forest ecosystems in North America. This rust pathogen is native to Asia and was introduced to North America in approximately 1910 through infected white pine seedlings. North American native five-needle pine trees were highly susceptible to this pathogen, especially seedlings and young trees which were more easily infected and killed by this pathogen. Thus, the substantial damage and mortality caused by this disease has had significant commercial and ecological impact on fiveneedle pine species, including western white pine, eastern white pine, limber pine, and whitebark pine in Canada. With continuous spread of this disease, the cascading effects on ecology are obvious (Sniezko et al. 2014). To complete its life cycle, this pathogen requires two hosts, a five-needle pine and a currant or gooseberry plant (Ribes spp.). The pathogen infects five-needle pine trees through stomata openings or wounds as its spores germinate and grow on the surface of needles or barks. In the early period of symptom development, indistinct chlorotic spots form on needles. With spread of the fungus to branches, bark tissue forms spindleshaped swellings, then forms cankers, and most infected trees are eventually killed in the next season or a few years (Maloy 2003).

Rust fungi secret effectors which interfere with host metabolism to facilitate infection and colonization (Dodds and Rathjen 2010). Interaction between effectors encoded by avirulence (Avr) genes and the corresponding resistance $(\mathrm{R})$ proteins initiates downstream gene expression, which results in incompatible host-pathogen

${ }^{\dagger}$ Corresponding author: J.-J. Liu; E-mail: Jun-jun.liu@canada.ca

Funding: This research was supported, in part, by the CFS-GRDI, and Z. Ma was supported by a postdoctoral fellowship funded by CFS-NRCan.

*The $\boldsymbol{e}$-Xtra logo stands for "electronic extra" and indicates that one supplementary file, two supplementary figures, and four supplementary tables are published online.

The author(s) declare no conflict of interest.

(C) Her Majesty the Queen in Right of Canada, as represented by the Minister of Agriculture and Agri-Food Canada, 2019. interaction (Kushalappa et al. 2016). Following signal transduction in host cells during incompatible host-pathogen interaction, plants generate a race-specific hypersensitive response (HR) referred to as effector-triggered immunity or qualitative resistance (Kushalappa et al. 2016), or major gene resistance (MGR) in breeding and conservation of five-needle pine trees. According to gene-for-gene theory, $R$ genes are present in hosts and their product $\mathrm{R}$ proteins recognize fungal effectors to initiate downstream reactions, leading to race-specific HR or cell death in order to prevent spread or further infection by the pathogens (Kushalappa et al. 2016). If $\mathrm{R}$ proteins are absent in hosts, corresponding effectors will promote virulence of pathogens through inhibiting pathogen-associated molecular pattern-triggered immunity in plants, called effector-triggered susceptibility (ETS). ETS plays a crucial role in early stages of the infection process, and expression of effector genes and ETS reaches to a peak level at the same time (Vleeshouwers and Oliver 2014). In the process of compatible host-pathogen interaction for successful colonization inside plant tissues, rust fungi form haustoria in different shapes to penetrate the cell wall and increase surface area to contact the plasma membrane of host cells to absorb nutrients and transport effector proteins into the host cells (Rafiqi et al. 2012).

Eight effectors have been identified in rust fungi, including AvrM, AvrL567, AvrP123, and AvrP4 in Melampsora lini, causing flax rust (Catanzariti 2006; Rafiqi et al. 2010); RTP1 in Uromyces fabae, causing bean rust (Kemen et al. 2005); and RGDBP, VPS9, and PGTAUSPE-10-1 in Puccinia graminis f. sp. tritici, causing wheat stem rust (Nirmala et al. 2011; Upadhyaya et al. 2014), all of which are expressed in haustoria. Rust effectors are translocated from haustoria into host cells in the process of infection. The effectors AvrP4, AvrM, and AvrL567 move into plant cells autonomously, even in the absence of the fungus on plants (Catanzariti 2006; Dodds 2004). However, the translocation mechanism of effectors is unknown. One possible way is that effectors are transported by a specialized translocation apparatus in fungi. Another possibility is through a cross-membrane transport mechanism of plants (Catanzariti 2006). The specialized translocation apparatus possibly is produced by infectious hyphae or haustoria, and the cross-membrane system for transportation could 
be from fungi, plants, or a combination of cross-membrane systems of plants and fungi. Data on AvrL567 show that transportation carriers (a type of phospholipid, phosphatidylinositol-3-phosphate, that effectors bind to) are needed for transportation of effectors from the fungus to plant cells (Kale et al. 2010). AvrP4, AvrM, and AvrL567 have been confirmed to have signal peptides (Catanzariti 2006; Dodds 2004).

In addition, N-terminal domains of effectors contain hydrophobic residues which mediate and facilitate penetration of host cell membranes (Rafiqi et al. 2010; Ve et al. 2013). A conserved RXLR (Arg-Xaa-Leu-Arg) motif in the N-terminal domain of a secreted signal peptide found in oomycetes is required for secretion and translocation of effectors (Win et al. 2007). A Y/F/WxC motif has been found in Blumeria graminis f. sp. hordei, causing barley powdery mildew disease, and $P$. graminis f. sp. tritici, causing wheat leaf rust disease (Godfrey et al. 2010). Both RXLR and Y/F/WxC effectors are produced by haustoria but biological functions of the latter are unknown. Even though they are found to be unnecessary for translocation, the motifs play a key role in evolution of the pathogens and classification of effectors (Win et al. 2007).

These characterized rust effectors were encoded by specific Avr genes in pathogens, except for RTP1, which was undetermined (Petre et al. 2014). They have either Avr or non-Avr characteristics but how these rust effectors work inside susceptible host tissues to promote fungal growth is unknown. Effectors secreted by pathogens have varying functions; some are needed to suppress plant immunity, others may hijack the host cell metabolism or have other unknown functions. They may either stimulate or downregulate expression of immune systems in plants. For example, a Phytophthora sojae effector improves disease resistance in tobacco (Zhang et al. 2015) but effector proteins ATR1 and ATR13 of Hyaloperonospora parasitica enhance disease susceptibility in Arabidopsis (Sohn et al. 2007). Effectors from poplar rust fungus increase growth of Pseudomonas syringae in Arabidopsis leaves (Germain et al. 2018).

Interaction between pathogens and hosts involves expression of numerous genes related to plant disease resistance or defense response. Nonexpresser of pathogenesis-related genes 1 (NPRI) is a receptor of salicylic acid (SA) synthesized by isochorismate synthase 1/salicylic acid induction deficient 2 (SID2) (Wildermuth et al. 2001).Their interaction activates downstream immune systems such as expression of pathogenesis-related (PR) proteins. However, NPR3 and NPR4 play an opposite role as compared with $N P R 1$. Loss of NPR3 and NPR4 in plants increases expression of PR proteins (Ding et al. 2018). PR proteins play an important role in disease resistance and some of their functions are known. $P R 1, P R 4$, and $P R 5$ are antifungal; $P R 2$ cleaves $\beta$-1,3-glucans; and $P R 3$ encodes endochitinase (Sinha et al. 2014). Enhanced disease susceptibility 5 (EDS5) and phytoalexin deficient 4 (PAD4) are signaling components in SA-induced disease resistance and their mutants increase disease susceptibility in Arabidopsis (Venugopal et al. 2009). Thiosulfate/3-mercaptopyruvate sulfurtransferase 2 (SRT2) is a negative regulator in SA-induced disease resistance in Arabidopsis (Wang et al. 2010). Plant defensin 1.2 (PADF1.2) is induced by pathogen infection or methyl jasmonate but independent of SA (Penninckx et al. 1996; Vijayan et al. 1998). Transcription factor WRKY12 is required for expression of PR proteins (van Verk et al. 2008), and WRKY genes positively regulate expression of NPRl and function upstream of NPRI (Yu et al. 2001). Coronatine insensitive 1 (COII) is a receptor of jasmonate and phytotoxin coronatine (Katsir et al. 2008; Yan et al. 2009), playing a key role in the jasmonic acid (JA) signaling pathway. The ethylene and jasmonate signaling pathways converge at downstream ethylene response factor 1 (ERF1) and expression of ERF1 suppresses disease development (Lorenzo et al. 2003). Abscisic acid 1 (ABA1) has an antagonistic function to the jasmonate-ethylene signaling pathway (Anderson 2004). Expression of HSR201 and HSR203J is independent of the SA or JA signaling pathways but their expression is relative to HR (Czernic et al. 1996; Pontier et al. 1994). Proteinase inhibitor 1 (PII) and endochitinase B are not in the SA, $\mathrm{JA}$, or ethylene signal pathways but their expression increases disease resistance of plants (Gupta et al. 2013; Juge 2006; Raffaello and Asiegbu 2017). Therefore, exploring the expression of these genes will be of interest when investigating the interaction between pathogens and hosts or nonhosts.

Because plant pathogens secrete effectors to interfere with the host's biological functions and cause diseases, determining the effectors' function is essential for understanding pathogenic mechanisms of pathogens. This study area formed a branch called effector biology to further understand molecular interactions of effectors with their targets in host plants (Hogenhout et al. 2009). In addition, effectors are now considered to be functional markers to accelerate and improve disease resistance breeding (Vleeshouwers and Oliver 2014). However, studying the function of rust fungal effectors is challenging because these pathogens are obligate biotrophs, very difficult to culture, and their spores often lose viability during storage. At present, 8 effectors from rust pathogens have been reported even though at least 82 effectors from plant pathogens have been published (Petre et al. 2014; Selin et al. 2016). It is even more challenging to study the function of effector proteins of $C$. ribicola on its hosts because needles of five-needle pine trees are small and hard, making them difficult to perform experiments on. In addition, to culture seedlings of five-needle pine is time and labor consuming. From breaking seed dormancy to obtaining seedlings with sufficiently large needles requires 6 months or longer. Therefore, it is more feasible to research the function of C. ribicola effectors on model plants such as Arabidopsis and tobacco. If candidate effectors are selected, these genes can be transformed into plant cells to explore their putative functions by agroinfiltration (Yang et al. 2000) or agroinfection (Grimsley et al. 1986). Similar research has been done using tobacco (Bhadauria et al. 2013; Stotz et al. 2014) and Arabidopsis (Caillaud et al. 2013; Chiang and Coaker 2015; Iakovidis et al. 2016; Wroblewski et al. 2005). For example, type III effectors from $P$. syringae were expressed transiently in tobacco leaves (Buyel et al. 2015) and the effector HaRxL62 was stably expressed in Arabidopsis (Asai et al. 2014).

Although $C$. ribicola candidate effectors were mined by bioinformatics prediction in the transcriptome with putative roles in the interactions between this lethal pathogen and five-needle pine (Liu et al. 2015), thus far, no effectors of $C$. ribicola were functionally characterized. Furthermore, only one $R$ gene, $\mathrm{Cr} 2$, was found in western white pine (Kinloch et al. 1999) and its frequency of geographic distribution is very low, at $0.1 \%$ range wide (Kinloch et al. 2003; Vogan and Schoettle 2015). MGRs have been applied in breeding of five-needle pine but the specific $R$ genes may be easy to overcome. Thus, to find effectors of $C$. ribicola and figure out their functions is of great importance, by which we could further understand the mechanism of $C$. ribicola infection of its hosts. The identified effectors can also be used to discover additional $R$ genes in five-needle pine by gene-for-gene theory, and this will provide more opportunity and crucial reference for breeding of western white pine and other five-needle pine species. In this study, C. ribicola candidate effectors were first screened by their transient expression in tobacco leaves, and one of them was then selected for further functional verification by its stable expression in transgenic Arabidopsis.

\section{MATERIALS AND METHODS}

Plant and bacterial material and their growth conditions. The tobacco (Nicotiana benthamiana) wild type, Arabidopsis thaliana (Col-0) wild type, and transformed Arabidopsis were planted in PV Perl soil (peat-vermiculite-perlite [3:1:1], with Osmocote 18-6-12 fertilizer) in a growth chamber. A photoperiod was $16 \mathrm{~h}$ in light with intensity at 14 Klux and $8 \mathrm{~h}$ in darkness. 
Temperature was $25^{\circ} \mathrm{C}$ in daytime and $20^{\circ} \mathrm{C}$ at night. The seedlings were fertilized once a week with Plant-Prod all-purpose 20-20-20 fertilizer $\left(0.5 \mathrm{~g} /\right.$ liter of $\left.\mathrm{H}_{2} \mathrm{O}\right)$. When tobacco seedlings were 4 to 5 weeks old, only the top, almost fully developed leaves were used for agroinfiltration and bacterial inoculation experiments. When Arabidopsis seedlings were 4 weeks old, the fully developed leaves at the base were used in experimental treatments. Each treatment had at least three biological repeats.

For gene transformation, Agrobacterium tumefaciens GV3101 resistant to rifampicin and gentamicin and Library Efficiency DH5 $\alpha$ Chemically Competent Cells (Thermo Fisher Scientific) were used. If it was necessary, rotation speed at $250 \mathrm{rpm}$ was set to culture bacterial suspension. A. tumefaciens GV3101 and P. syringae Psm ES4326 resistant to streptomycin at $50 \mathrm{mg} / \mathrm{liter}$ had the same culture conditions for growth at $28^{\circ} \mathrm{C}$. The culturing temperature of Escherichia coli DH5 $\alpha$ was $37^{\circ} \mathrm{C}$. Bacterial culture medium was Luria-Bertani (LB) broth (Sigma) or LB broth with agar (Sigma), except that super optimal broth with catabolite repression was used to culture competent cells.

RNA extraction and cDNA synthesis. RNA was extracted using a protocol of the RNeasy Plant Mini Kit (Qiagen), with the following modifications at the first step. For RNA extraction from urediniospores or aeciospores, approximately $100 \mathrm{mg}$ of fresh spores were ground in $1 \mathrm{ml}$ of buffer RLT with mortars and pestles for $15 \mathrm{~min}$. For RNA extraction from Arabidopsis or tobacco leaves, the leaves were ground into fine powder in liquid nitrogen and, next, approximately $100 \mathrm{mg}$ of powder was homogenized in $0.8 \mathrm{ml}$ of buffer RLT by further grinding for $3 \mathrm{~min}$. For RNA extraction from bark tissue of western white pine or Ribes leaves, the plant tissue was ground into fine powder in liquid nitrogen with mortars and pestles. Approximately $100 \mathrm{mg}$ of fine powder was mixed with $1 \mathrm{ml}$ of extraction buffer $(0.1 \mathrm{M}$ Tris- $\mathrm{HCl}, 0.5 \mathrm{M} \mathrm{NaCl}, 50 \mathrm{mM}$ EDTA, 2\% sodium dodecyl sulfate, 2\% PVP-40, and $10 \mathrm{mM}$ $\beta$-mercaptoethanol added freshly before use; $\mathrm{pH}$ 7.4) by grinding for another $5 \mathrm{~min}$. All of the later steps followed the manufacturer's protocol. RNA integrity was observed in a $1 \%$ agarose gel by loading $1 \mu \mathrm{g}$ of RNA into wells.

RNA solution was treated by DNase 1 (TURBO DNA-free Kit; Ambion) to get rid of contamination of genomic DNA, following the manufacturer's manual. cDNA was synthesized following the protocol of the SuperScript VILO cDNA Synthesis Kit (Invitrogen).

Vector construction. Based on previous work (Liu et al. 2015), three candidate effector genes-Cri-9402 (852 bp), Cri-13229 (552 bp), and Cri-71057 (285 bp)—were selected to recombine them into an empty binary vector, pK7WG2D,1 (Karimi et al. 2002), for gene expression in higher plants using Gateway technology, following the manufacturer's protocols (Invitrogen). In brief, polymerase chain reaction (PCR) primers were designed for the candidate effectors and the empty vector (Supplementary Table S1). Because $c c D B$ is toxic to $P$. syringae Psm ES4326 (Bernard 1996), it was replaced by a fragment (218 bp) of $35 \mathrm{~S}$ promoter in the empty pK7WG2D,1. The length of each PCR product was the length of each target gene fragment plus $61 \mathrm{bp}$ from primers of Gateway technology. PCR products of the candidate genes and control were amplified following a program of 1 cycle of $95^{\circ} \mathrm{C}$ for $5 \mathrm{~min} ; 35$ cycles of $96^{\circ} \mathrm{C}$ for $20 \mathrm{~s}, 50^{\circ} \mathrm{C}$ for $15 \mathrm{~s}$, and $60^{\circ} \mathrm{C}$ for $4 \mathrm{~min}$; and 1 cycle of $60^{\circ} \mathrm{C}$ for $10 \mathrm{~min}$. Urediniospore cDNA and the empty vector pK7WG2D,1 were used as PCR templates for candidate effectors and 35S fragment, respectively. The PCR products were purified by the MinElute Gel Extraction Kit (Qiagen) and cloned into pDONR221 to form entry clones. The entry clones were sequenced at Applied Biological Materials Inc. Following sequence verification, a targeted sequence of each entry clone was recombined into the empty binary vector $\mathrm{pK} 7 \mathrm{WG} 2 \mathrm{D}, 1$. At this step, the $c c D B$ sequence in the binary vector was replaced by the candidate genes and the $35 \mathrm{~S}$ promoter fragment, respectively. These binary vectors were finally transformed into A. tumefaciens
GV3101 by electroporation for transgenic expression in plant tissues.

Screening candidate effectors in tobacco leaves through interaction with $P$. syringae Psm ES4326. Single colonies of A. tumefaciens GV3101 containing each of the candidate effectors or the modified empty vector as a negative control were cultured overnight, with shaking, in $5 \mathrm{ml}$ of LB broth containing rifampicin at $100 \mu \mathrm{g} / \mathrm{ml}$, kanamycin at $50 \mu \mathrm{g} / \mathrm{ml}$, and spectinomycin at $80 \mu \mathrm{g} / \mathrm{ml}$. The bacterial suspension ( $1 \mathrm{ml}$ ) was transferred into $50 \mathrm{ml}$ of LB broth containing the same antibiotics, $100 \mu \mathrm{M}$ acetosyringone, and $10 \mathrm{mM} \mathrm{MgCl} 2$ in 250-ml flasks and cultured for another day under the same conditions. Bacteria were collected by centrifugation at $7,000 \times g$ for $5 \mathrm{~min}$ and washed twice with infiltration buffer (10 mM morpholineethanesulfonic acid, $100 \mu \mathrm{M}$ acetosyringone, $0.005 \%$ Tween 20 , and $10 \mathrm{mM} \mathrm{MgCl}_{2} ; \mathrm{pH}$ 5.6). The final concentration of Agrobacterium was adjusted to an optical density at $600 \mathrm{~nm}\left(\mathrm{OD}_{600}\right)$ of $0.2 \pm 0.01$. After the bacterial suspension stood at room temperature for at least $3 \mathrm{~h}$, it was infiltrated into the top almost fully developed leaves on 4- to 5-week-old tobacco seedlings by a needleless syringe and the area was marked on the back side of leaves. Single colonies of $P$. syringae Psm ES4326, which causes necrotic spots on leaves of $N$. benthamiana, were cultured in LB broth containing streptomycin at $50 \mu \mathrm{g} / \mathrm{ml}$ and the bacterium was collected by the same methods as that for Agrobacterium. The final cell density of $P$. syringae Psm ES4326 was adjusted to an $\mathrm{OD}_{600}$ of 0.1 in $0.005 \%$ Tween 20 . After $24 \mathrm{~h}$ of the candidate genes being agroinfiltrated into tobacco leaves, $P$. syringae Psm ES4326 was infiltrated into tobacco leaves. If the bacteria were infiltrated into the same area of the candidate genes or empty vector, the infiltrated area of $P$. syringae Psm ES4326 should be a little smaller than that of the candidate genes or control. On each treated tobacco leaf, there were five infiltrated areas: candidate effector, candidate effector $+P$. syringae Psm ES4326, control (modified empty pK7WG2D,1), control + P. syringae Psm ES4326, and $P$. syringae Psm ES4326. The symptoms were observed after $36 \mathrm{~h}$ post bacterial inoculation.

Generation of transgenic Arabidopsis. Transgenic Arabidopsis seed were generated following the floral dip method (Clough and Bent 1998). The Arabidopsis plants were grown for approximately 4 weeks. During this period, the first bolts were cut off to stimulate more secondary ones to grow. Suspensions of A. tumefaciens GV3101 containing the Cri-9402 expression vector or the modified empty vector pK7WG2D,1 were prepared. The suspensions were adjusted to approximately $\mathrm{OD}_{600}=0.8$ in $5 \%$ sucrose solution in a volume large enough to submerge the Arabidopsis seedlings. Before dipping Arabidopsis seedlings, Silwet L-77 (Bioworld) was added to a final concentration of $0.05 \%$. The aboveground parts of the Arabidopsis seedlings were dipped into the Agrobacterium suspension for $1 \mathrm{~min}$ with gentle agitation. The dipped seedlings were covered with plastic bags to keep moisture for $48 \mathrm{~h}$. The seedlings were dipped into Agrobacterium suspension once per week for a total of three times. After approximately another month, the seed were harvested.

The Arabidopsis seed were sterilized in $2 \%$ hypochloric acid for 10 min and rinsed four times with sterile double-distilled (dd) $\mathrm{H}_{2} \mathrm{O}$. The wet seed were stored in a $4^{\circ} \mathrm{C}$ fridge for 3 days to break dormancy. Next, the seed were spread on Murashige and Skoog medium plates containing kanamycin at $80 \mu \mathrm{g} / \mathrm{ml}$, incubated in darkness at $25^{\circ} \mathrm{C}$ for 3 days, then incubated under continuous light for 4 days. The seedlings that became green were transferred to PV Perl soil. For each binary vector, six transgenic kanamycin-resistant Arabidopsis seedlings were chosen. When the seedlings were approximately 4 weeks old, RNA was extracted from the leaves at the base and used to synthesize cDNA for PCR to confirm presence of the candidate gene; transgenic seedlings by modified empty vector and wild-type seedlings were used as negative controls. The PCR program consisted of 1 cycle of $95^{\circ} \mathrm{C}$ for $5 \mathrm{~min}$; 40 cycles of $95^{\circ} \mathrm{C}$ for $30 \mathrm{~s}, 60^{\circ} \mathrm{C}$ for $30 \mathrm{~s}$, and $72^{\circ} \mathrm{C}$ for $1 \mathrm{~min}$; and 1 final cycle of 
$72^{\circ} \mathrm{C}$ for $10 \mathrm{~min}$. The $\mathrm{PCR}$ products were run in $1 \%$ agarose gel for 40 min under $90 \mathrm{~V}$.

Growth of $P$. syringae Psm ES4326 in tobacco or Arabidopsis leaves. A suspension $\left(\mathrm{OD}_{600}=0.2\right)$ of $A$. tumefaciens GV3101 containing the Cri-9402 expression vector was infiltrated into the top almost fully developed tobacco leaves by needleless syringes and the infiltrated area was marked at the back. After $24 \mathrm{~h}$, a suspension of $P$. syringae Psm ES4326 $\left(\mathrm{OD}_{600}=0.1\right)$ was infiltrated into the same area, again marked clearly (a little smaller). Before collecting leaf samples, the whole leaves were sterilized with $2 \%$ hypochlorous acid for $5 \mathrm{~min}$, rinsed four times with sterile $\mathrm{dd}_{2} \mathrm{O}$, and dried gently using sterile delicate task wipers (Kimteck Science). Leaf discs from the area infiltrated with P. syringae Psm ES4326 were collected into lysing matrix A tubes every day from day 0 to day 4 by a hole puncher $($ diameter $=0.8 \mathrm{~cm})$. The tubes were flash frozen in liquid nitrogen and homogenized twice using a FastPrep-24 (MP Biomedicals) with speed at $6 \mathrm{~m} / \mathrm{s}$ for $10 \mathrm{~s}$. Extraction buffer containing $0.005 \%$ Tween 20 and $10 \mathrm{mM} \mathrm{MgCl}_{2}$ ( $0.4 \mathrm{ml}$ per two discs) was added into the tubes and vortexed vigorously until the bacterial suspension was homologous. The freshly prepared bacterial suspension $(20 \mu \mathrm{l})$ diluted from $10^{1}$ to $10^{6}$ in the extraction buffer was dropped on the LB plate containing streptomycin at $50 \mu \mathrm{g} / \mathrm{liter}$, and the plates stood on a sterile bench until the bacterial drops dried. Because a lot of $P$. syringae Psm ES4326 would die in extraction buffer after overnight storage at room temperature, $4^{\circ} \mathrm{C}$, or $-20^{\circ} \mathrm{C}$, bacterial extraction from leaf tissues and its incubation were performed on the same day. After the plates were incubated in an incubator for $48 \mathrm{~h}$ in darkness, the number of colonies was counted. To observe the growth of $P$. syringae Psm ES4326 in transgenic Arabidopsis leaves, the same method as the above was followed but without infiltrating $A$. tumefaciens GV3101 containing the Cri-9402 expression vector into the plant leaves.

Real-time PCR analysis of gene expression in tobacco and Arabidopsis leaves. To investigate the effect of transient expression of Cri-9402 in tobacco, leaf samples were collected at 0 (fresh leaves), 6 , and $24 \mathrm{~h}$ after infiltration of A. tumefaciens GV3101 containing the Cri-9402 expression vector. Expression of disease-resistance-related genes $P R 1, P R 2, P R 3, P R 4 a$, WRKY12, HSR203J, endochitinase B, PII, PDF1.2, ABA1, ERF1, and COI1 was determined by real-time PCR (RT-PCR) and the tobacco actin gene was taken as the internal control (PCR primers listed in Supplementary Table S2). RNA extraction from plant tissue and cDNA synthesis were performed as above described. To estimate gene expression related to host resistance in Arabidopsis seedlings induced by the candidate effector Cri-9402, the leaves at base of 4week-old seedlings were collected for RNA extraction and cDNA synthesis as described above. The expression of $P R 1, P R 2, P R 3$, PR4, PR5, NPR1, NPR3, NPR4, EDS5, SID2, PAD4, PDF1.2, and
SRT2 in transgenic Arabidopsis was tested and the Arabidopsis actin $2 / 8$ gene was taken as the internal control (PCR primers listed in Supplementary Table S3). SYBR Select Master Mix (Applied Biosystems) and 7500 Fast Real-Time PCR System (7500 Fast Software, version 2.3; Applied Biosystems) were used in all of the RT-PCR in this research. The program for RT-PCR consisted of hold at $50^{\circ} \mathrm{C}$ for $2 \mathrm{~min}$, hold at $95^{\circ} \mathrm{C}$ for $2 \mathrm{~min}$, and 40 cycles of $95^{\circ} \mathrm{C}$ for $15 \mathrm{~s}$ and $60^{\circ} \mathrm{C}$ for $1 \mathrm{~min}$. To determine the expression of Cri-9402 in transgenic Arabidopsis the same RT-PCR methods as the above were followed but each biological sample had four technical repeats.

Transcript expression of Cri-9402 in spores and infected bark tissue of western white pine determined by RT-PCR. RT-PCR was used to determine transcript expression of Cri-9402 in aeciospores, urediniospores, canker, yellow bark tissue caused by infection, and green bark tissue next to the infected area. Bark tissue of healthy white pine and healthy Ribes leaves were taken as negative control, and $\alpha$-tubulin in the fungus was taken as internal control. The program for the RT-PCR consisted of hold at $50^{\circ} \mathrm{C}$ for $2 \mathrm{~min}$, hold at $95^{\circ} \mathrm{C}$ for $2 \mathrm{~min}$, and 40 cycles of $95^{\circ} \mathrm{C}$ for $15 \mathrm{~s}$ and $62^{\circ} \mathrm{C}$ for $1 \mathrm{~min}$.

Bioinformatics and statistical analyses. Sequence data provided by Applied Biological Materials Inc. were assembled by Sequencher DNA sequence analysis software, version 5.4.6 (Gene Codes Corporation). Blast searches of DNA and protein sequences were performed online using Blastn, Blastx, and Blastp under the National Center for Biotechnology Information (NCBI). Protein sequences of the candidate genes were translated using ExPASy (Bioinformatics Resource Portal), and protein sequence alignment was performed online using Clustal Omega. The statistical calculation of data in this report was done using R-3.5.1 downloaded online. Two-way analysis of variance was used to compare differences between time points and samples.

\section{RESULTS}

Interaction between candidate effectors and $P$. syringae Psm ES4326 growth to show Cri-9402 as an effector. Following infiltration of $P$. syringae Psm ES4326 into areas pretreated by the candidate genes Cri-9402, Cri-13229, and Cri71057, only Cri-9402 inhibited production of necrotic spots on tobacco leaves but the modified empty vector did not (Fig. 1A). Thus, this candidate effector prevented HR caused by $P$. syringae Psm ES4326. Based on this finding, Cri-9402 was considered to be a C. ribicola effector. Cri-13229 did not prevent HR caused by $P$. syringae Psm ES4326 and the sizes of the necrotic spots caused by the bacteria on the areas infiltrated by the candidate gene and modified vector $\mathrm{pK} 7 \mathrm{WG} 2 \mathrm{D}, 1$ were similar (Fig. 1B). P. syringae Psm ES4326 caused yellow spots on the areas of tobacco leaves infiltrated with Cri-71057 and modified vector pK7WG2D,1,
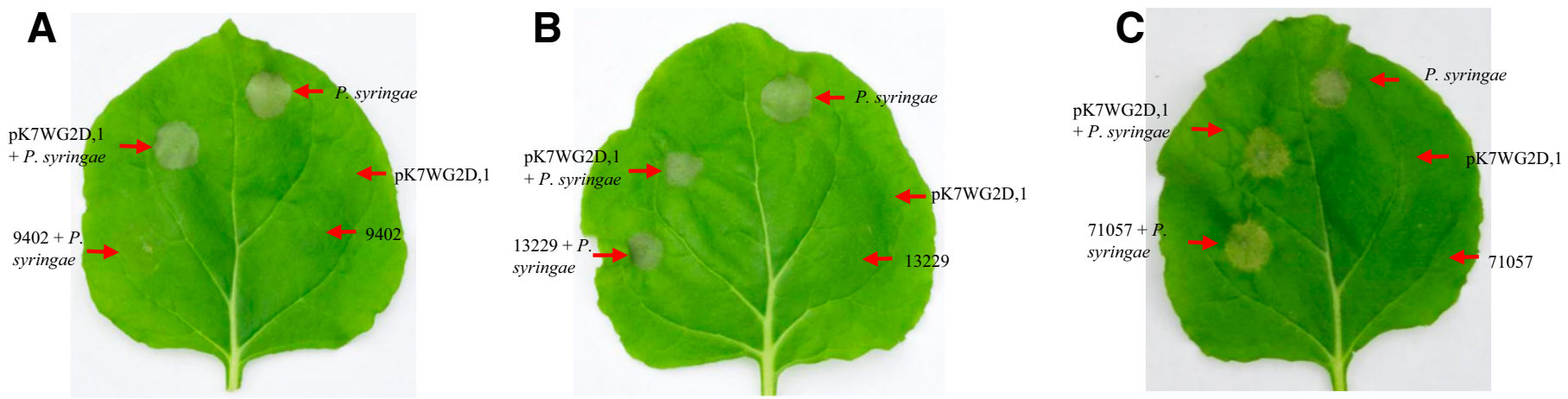

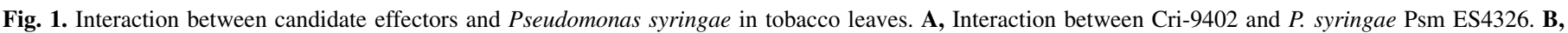

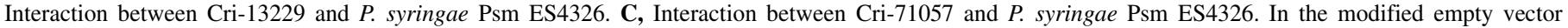
pK7WG2D, $c c D B$ was replaced by a fragment of $35 \mathrm{~S}$ promotor. 
respectively, and both of them suppressed necrosis caused by P. syringae Psm ES4326 under our experimental conditions (Fig. 1C). Therefore, Cri-13229 and Cri-71057 were not considered as effectors for further functional analysis.

Screening of transgenic Arabidopsis seedlings with Cri9402 expression. Following floral dip by Agrobacterium, the harvested seed were germinated on selective LB plates containing kanamycin at $80 \mu \mathrm{g} / \mathrm{ml}$. Transformed Arabidopsis seed containing Cri-9402 or the modified vector pK7WG2D,1 as control formed green seedlings because they were kanamycin-resistant. Furthermore, the size of the transformed seedlings was bigger than the nontransformed ones (Supplementary Fig. S1). The nontransformed seedlings were yellow and dying because they were not kanamycin-resistant.

To further confirm that the transgenic Arabidopsis seedlings with expression of Cri-9402 or the modified empty vector, PCR was performed using cDNA templates and the size of the PCR products was analyzed on agarose gels. The sizes of the PCR products of Cri9402 and the modified empty vector appeared at the correct migration positions on the agarose gel. In the wild-type Arabidopsis, no PCR products were observed (Fig. 2A). Among the transgenic Arabidopsis seedlings, 9-1, 9-2, 9-3, 9-6, V-1, V-2, V-3, and V-4 were chosen for further experiments. RT-PCR was used to determine relatively precise expression of this gene in each transgenic Arabidopsis seedling and seedlings transformed by the modified empty vector were taken as control. Expression of Cri9402 in the four chosen seedlings was similar $(P>0.05)$ and no expression of it was observed in Arabidopsis seedlings with the modified vector pK7WG2D,1 (Fig. 2B).

Growth of $P$. syringae Psm ES4326 in tobacco leaves and Arabidopsis seedlings. In tobacco leaves with transient expression of Cri-9402, growth of $P$. syringae Psm ES4326 was slower than that in the control, suggesting that Cri-9402 might inhibit growth of $P$. syringae Psm ES4326 in tobacco leaves. Consistent with the symptoms observed in Figure 1A, the number of bacteria per leaf disc reached their peak values on day 2. The number of $P$. syringae Psm ES4326 per leaf disc was significantly $(P<0.05)$ less in tobacco leaves with transient expression of Cri-9402 than that in leaves with the modified empty vector pK7G2D,1 on day 2 but no
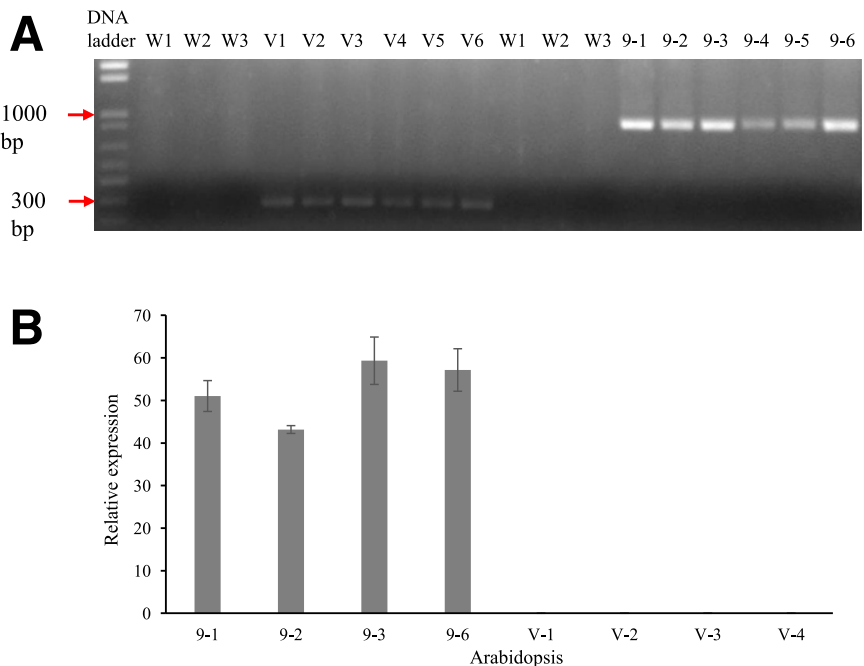

Fig. 2. Identification of transgenic Arabidopsis lines. A, Real-time polymerase chain reaction products shown on agarose gel. Lanes W1 to W3, Arabidopsis thaliana (Col-0) wild type seedlings; lanes V1 to V6, transgenic seedlings transformed by the modified empty vector pK7WG2D,1; and lanes 9-1 to 9-6: transgenic seedlings expressing Cri-9402. B, Relative expression levels of Cri9402 transcript in transgenic lines. Bars 9-1, 9-2, 9-3, and 9-6, transgenic seedlings expressing Cri-9402; and bars V1 to V4, transgenic seedlings transformed by the modified empty vector pK7WG2D,1. significant difference was observed on other days post bacterial inoculation (Fig. 3A).

In transgenic Arabidopsis seedlings with stable expression of Cri9402, the bacteria caused many more chlorotic spots on Arabidopsis leaves than on leaves transformed by the modified empty vector pK7WG2D,1, where almost no yellow spots were visible (Fig. 3B). The number of the bacteria per leaf disc reached a peak value on day 4 s postinoculation, and the number of $P$. syringae Psm ES4326 was significantly $(P<0.01)$ higher in Arabidopsis leaves expressing Cri9402 than in leaves transformed by the modified empty vector (Fig. $3 \mathrm{C})$. These results indicated that Cri-9402 stimulated growth of
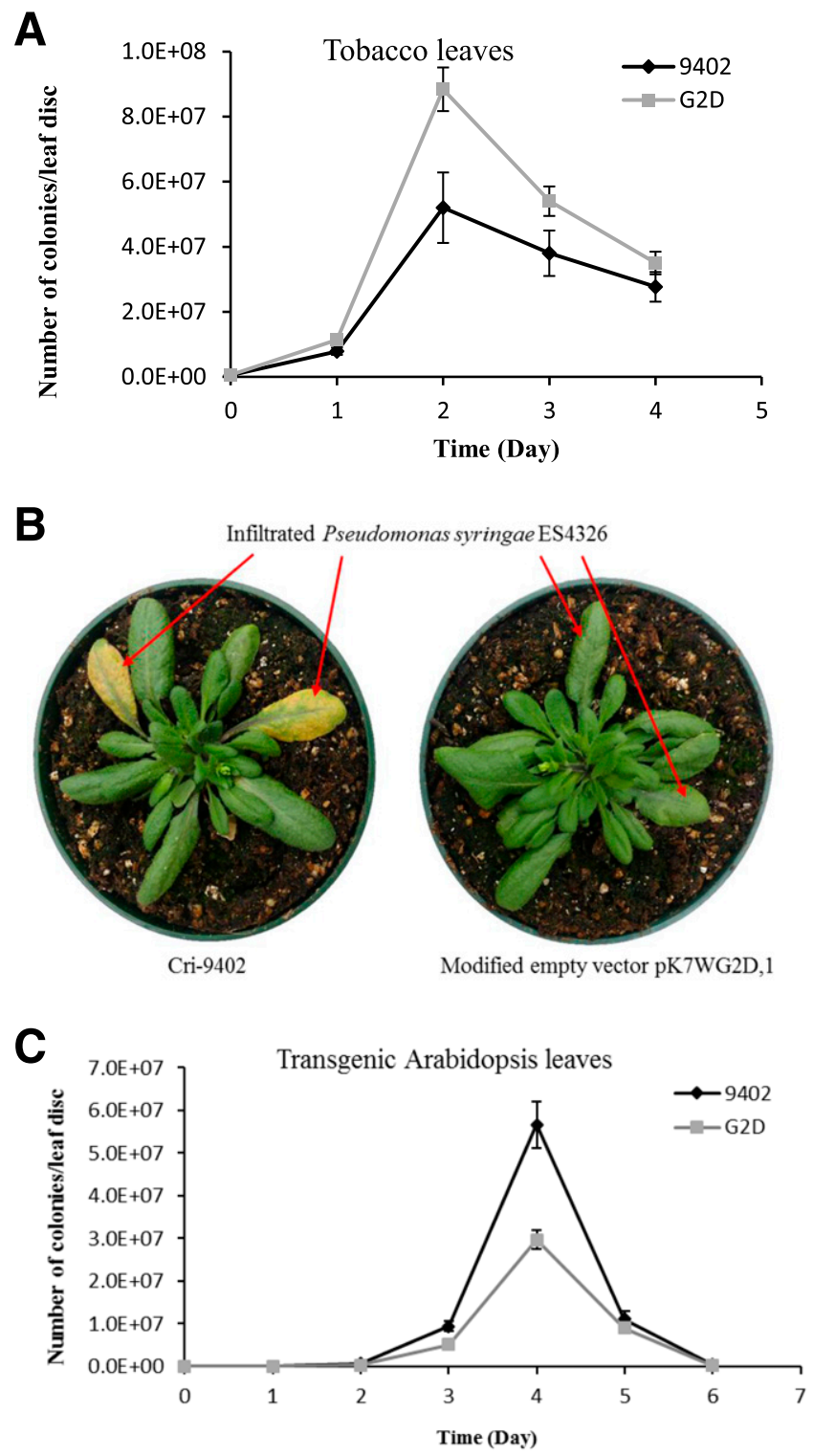

Fig. 3. Effect of Cri-9402 on bacterial growth. A, Growth of Pseudomonas syringae Psm ES4326 in tobacco leaves with transient expression of Cri-9402. The black line with diamond markers represented tobacco leaves with transient expression of Cri-9402 (9402). The gray line with square markers represented tobacco leaves containing modified empty vector pK7WG2D,1 (G2D). B, Symptoms caused by $P$. syringae ES4326 on transgenic Arabidopsis leaves. The seedling in the left pot expressed Cri-9402 and the seedling in the right pot was transformed by the modified empty vector pK7WG2D,1. Seedlings were 5 weeks old. Two leaves were infiltrated with P. syringae Psm ES4326 on each seedling, indicated by red arrows. C, Growth of P. syringae Psm ES4326 in transformed Arabidopsis leaves. The black line with diamond markers represented transformed Arabidopsis leaves expressing Cri-9402. The gray line with square markers represented Arabidopsis leaves transformed by the modified empty vector pK7WG2D,1. 
P. syringae Psm ES4326 in Arabidopsis seedlings with constitutive expression of Cri-9402.

Plant gene expression regulated by Cri-9402. Expression of PR2, PR3, PR4a, Endochitinase B, HSR201, HSR203J, PII, and $W R K Y 12$ was elevated in tobacco leaves from 0 to $24 \mathrm{~h}$ postinfiltration of Agrobacterium with Cri-9402, and their increase in leaves was significantly different $(P<0.01)$ between Cri-9402 and the empty vector at $24 \mathrm{~h}$ postinfiltration, except $W R K Y 12$ and $P R 3$ (Fig. 4). In contrast, expression of PR1, ERF1, COII, ABA1, and $P D F 1.2$ was inhibited by transient expression of Cri-9402 in tobacco leaves after infiltration for $24 \mathrm{~h}$, and expression of $P R 1$, $C O I 1$, and $A B A 1$ was suppressed significantly $(P<0.01)$ (Fig. 4).

In transgenic Arabidopsis seedlings with expression of Cri-9402, expression of $P R 1, P R 2, N P R 1, N P R 3, N P R 4, P A D 4$, and SID2 in leaf tissues was significantly lower $(P<0.01)$ compared with control plants (Fig. 5). On the other hand, expression of PDF1.2 in Arabidopsis leaves expressing Cri-9402 was significantly higher $(P$ $<0.01)$ than that in leaves transformed by the empty vector, showing that Cri-9402 stimulated expression of PDF1.2 (Fig. 5). Other tested genes (PR3, PR4, PR5, SRT2, and EDS5) showed no significant difference between Cri-9402- and empty-vectortransformed plants. These data indicated that Cri-9402 had a suppression effect on most of tested defense-related genes for their transcript expression in transgenic Arabidopsis plants.

Expression of Cri-9402 in spores and infected stems of western white pine. Transcript expression of Cri-9402 was the highest in aeciospores, and much higher than that in urediniospores and canker tissue. In canker tissue, its expression was higher than that in yellow bark tissue and green bark tissue next to the infected area, where its expression was undetectable, similar to the healthy green bark and Ribes leaves that were used as negative controls (Fig. 6).

Alignment of amino acid sequence of candidate effectors with their closest available proteins. No similar DNA sequences to the three candidate genes were found in nucleotide databases of NCBI using a Blastn search. Blastp search of putative
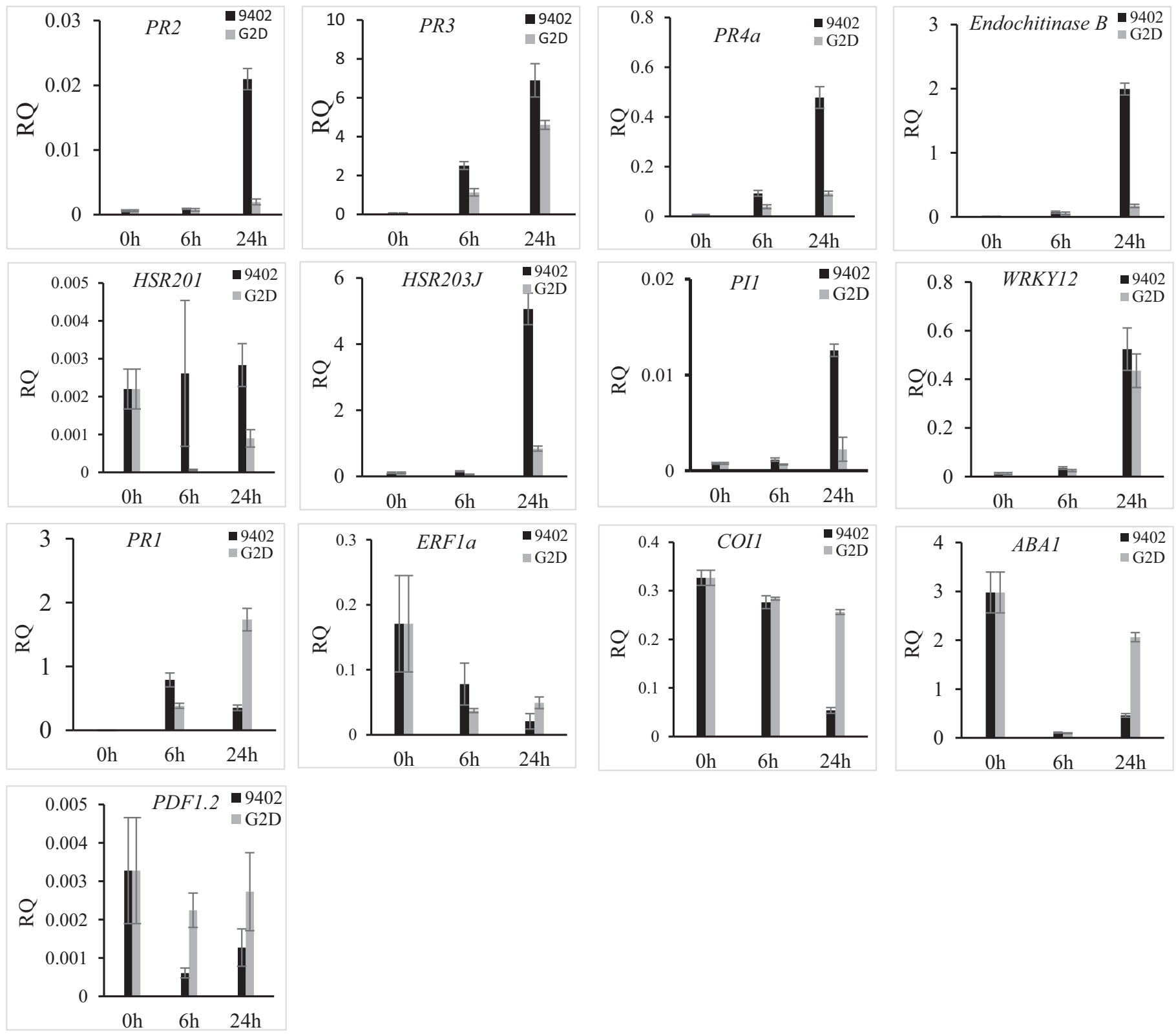

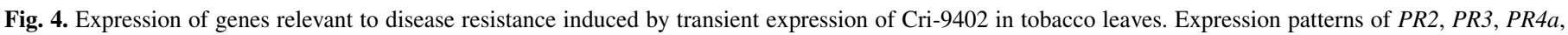

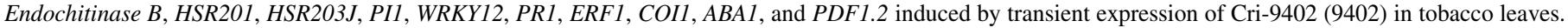
The modified empty vector pK7WG2D,1 (G2D) was used as a control. RQ = relative quantification as calculated by $2^{-\Delta \Delta C t}$. 
protein sequences Cri-9402 and Cri-13229 yielded significant matches but Cri-71057 did not. Similarity between Cri-9402 and XP_007405889.1 and between Cri-13229 and XP_007411526.1 was $43 \%$ and $71 \%$, respectively (Supplementary Fig. S2).

\section{DISCUSSION}

The dramatic rise in the availability of sequenced genomes or transcriptomes has facilitated the ability to screen effectors from thousands of candidate genes through computational tests and, thus, narrow the number of candidates for research in laboratories (Liu et al. 2015). Generally, fungal effectors do not share sequence similarity or conserved sequence motifs and they are small, secreted, and rich in cysteines (Sperschneider et al. 2015). In addition, if diverse selection criteria such as conservation, fungal pathogen genome, and induction in plants and expression in haustoria are taken into consideration to identify candidate effectors, the process of screening effector proteins is more credible and potential effector proteins are not easily overlooked (Sperschneider et al. 2014). The three chosen effector candidates in this report did not have any similar sequences in the NCBI nucleotide database. They were selected from transcriptome of $C$. ribicola aeciospores (Liu et al. 2015) and contained a certain number of cysteines (Supplementary Table S4). The data in this report showed that, of the three candidate genes, only Cri-9402 was an effector of C. ribicola, demonstrating that the size of the rust fungal effectors was not necessarily small but they were secreted proteins. What is more, the cysteine content of the effector was high $(4.5 \%)$, indicating that cysteines were important in biological functions of rust fungal effectors and could be key indicators of effectors (Sperschneider et al. 2015). To prevent cysteine proteases in hosts, it became essential to maintain biological functions of effectors in the interaction between effectors and host components (Mueller et al. 2013), and some rust effectors such as RPT1 were protease
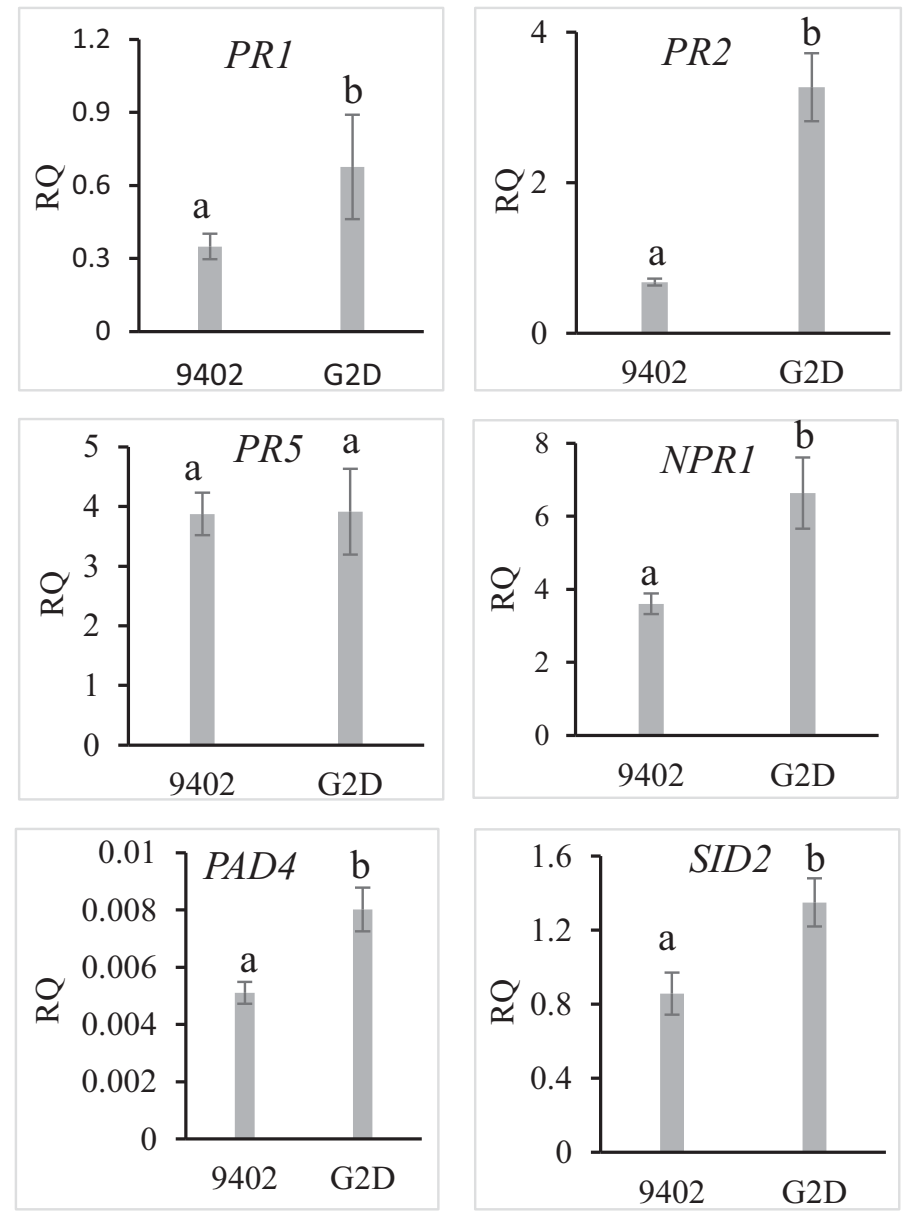
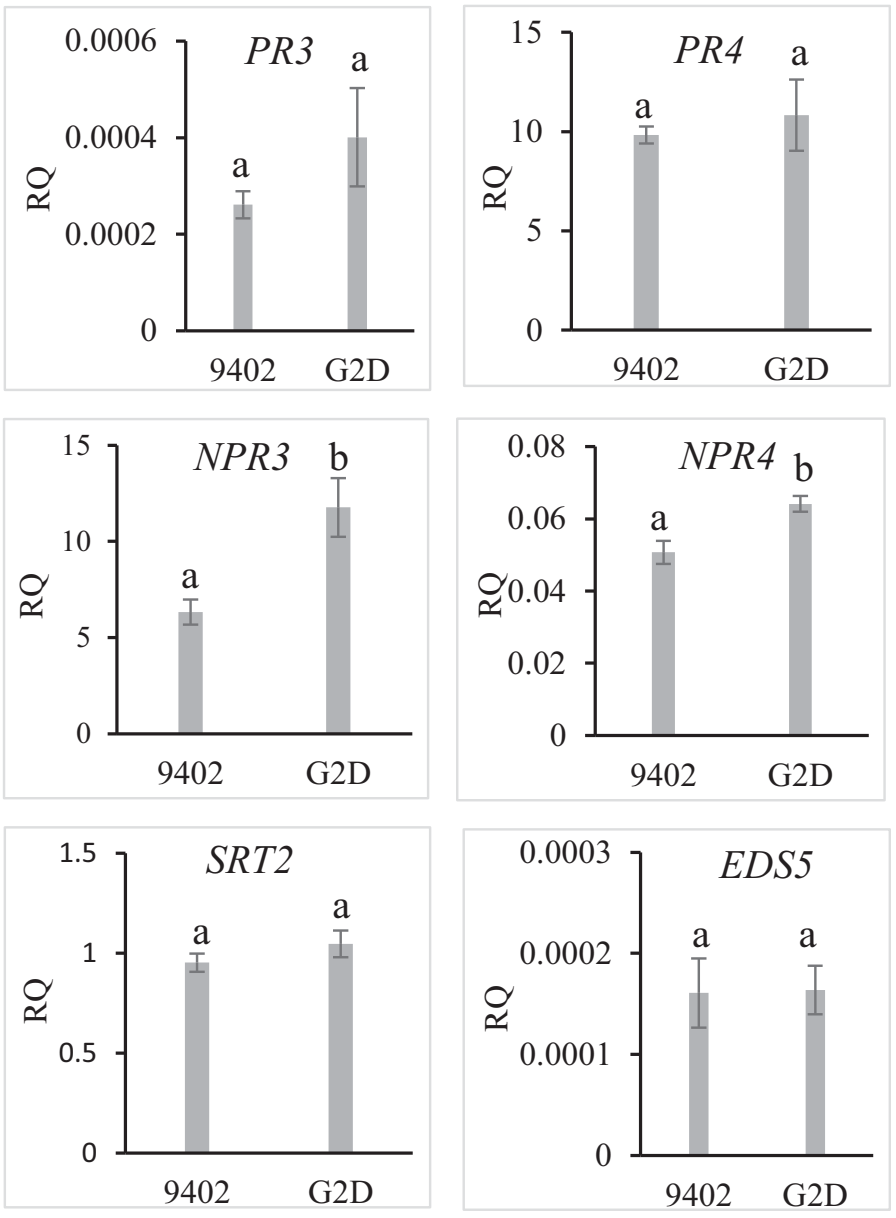

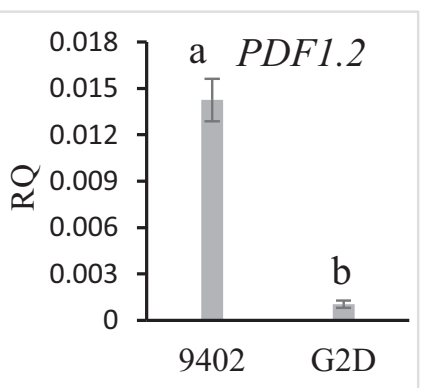

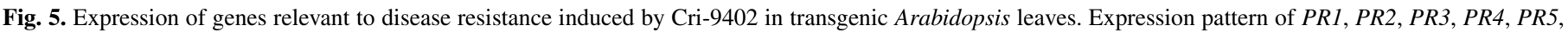

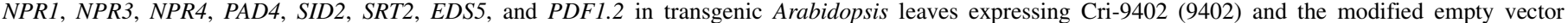
pK7WG2D,1 (G2D). Different letters represented statistically significant difference between samples. RQ $=$ relative quantification as calculated by $2^{-\Delta \Delta C t}$. 
inhibitors (Pretsch et al. 2013). Thus, based on the sequence information, not all small, secreted, cysteine-rich, and nonhomologous candidate proteins were effectors but they had some of these typical characteristics. Another interesting finding was that no similar DNA sequences were found in the NCBI nucleotide databases but some similar protein sequences were found in the NCBI protein database by Blastp search. Both $C$. ribicola homologous proteins (XP_007405889.1 and XP_007411526.1) are secreted by $M$. larici-populina 98AG31, a rust fungi on poplar leaves (Persoons et al. 2014). Even though Cri-13229 has $71 \%$ identity of amino acid sequence to XP_007411526.1, the data in this research did not show that it was an effector protein.

After computational prediction of effector candidates, confirmation of their roles as effectors must be done conclusively through functional verification. Many fungal effectors have been tested on tobacco leaves such as wheat rust fungal effector PEC6 (Liu et al. 2019a) and poplar rust fungal effector MLP124017 (Petre et al. 2015), demonstrating that the $N$. benthamiana-P. syringae interaction is a powerful heterologous system to study rust fungal effectors (Petre et al. 2015) because methodology has been well developed for this system (Ma et al. 2012). In this study, preinfiltration of Agrobacterium with the modified empty effector pK7WG2D,1 resulted in different symptoms on tobacco leaves after infection with $P$. syringae Psm ES4326 among biologically repeated samples. In wild-type tobacco leaves ( $N$. benthamiana), $P$. syringae Psm ES4326 caused typical necrotic spots (Fig. 1) but it caused different symptoms on areas of tobacco leaves preinfiltrated with Agrobacterium containing vectors of different candidate genes or the modified empty vector pK7WG2D,1 (Fig. 1). This was interesting and controversial. In published data, the empty vector did not interfere with HR caused by $P$. syringae but a different empty vector, A. tumefaciens strain, and $P$. syringae strain were used (Lee et al. 2018). This experiment disclosed complexity or some potential problems of this research system. However, the complexity or problems did not prevent Cri-9402 from being identified as a C. ribicola effector (Fig. 1), although some other possible effectors could be ignored using the tobacco-P. syringae system.

The number of $P$. syringae Psm ES4326 in leaves of control tobacco seedlings was 1.7 times higher than that in leaves with transient expression of Cri-9402 at their peak values (Fig. 3A). The effector inhibited production of HR and prevented quick death of leaf cells, which were beneficial to surviving, colonization, or infection of the obligate biotrophic pathogen on plants. Cri-9402 did not kill P. syringae Psm ES4326 in the tobacco leaves. It still had much proliferation in tobacco leaves expressing either Cri-9402 or the control vector, although Cri-9402 suppressed growth of the bacteria relative to the control. However, we found that many factors affected the results of the experiments. First of all, the effect of tobacco seedling's health on growth of P. syringae Psm ES4326 was notable. In theory, if the tobacco seedlings were healthy, their defense was difficult for $P$. syringae Psm ES4326 to break, and growth of it would be inhibited relatively. If tobacco seedlings were very weak, their defense systems could be easy to overcome. When tobacco seedlings had lower tolerance to P. syringae Psm ES4326, the bacteria would grow faster. Second, the dosage of the infiltrated bacteria had obvious effects on their growth tendency in tobacco leaves (Deng et al. 2010). One possible reason was that the health status of tobacco seedlings could vary, leading to different tolerance levels to infiltration of A grobacterium and $P$. syringae Psm ES4326. Furthermore, secreta of Agrobacterium or itself could have had some adverse effects on the interaction between target candidate genes and $P$. syringae Psm ES4326 growth. Although several factors interfered with screening candidate effectors or exploring their function using tobacco seedlings with transient gene expression compared with stable gene transformation, this system still has many advantages. For example, it is a short-term, 3- or 4-day transformation process and it is effective for investigating interaction between effector proteins and host or nonhost plants.
Using agroinfiltration to perform transient gene expression is cheap and easy to operate (Levy et al. 2005). In summary, this system is valuable and efficient to screen $C$. ribicola effector candidates or test their functions, although some interfering factors must be taken into consideration.

Testing the function of effector proteins through an Arabidopsis$P$. syringae pathosystem had been described in detail by Katagiri et al. (2002). This pathosystem has been applied widely and became a model for studying host-pathogen interactions. Especially, it conforms to the principle of gene-for-gene theory, by which this pathosystem becomes a powerful driving force in studying gene functions or looking for $R$ or effector genes. Many new genes and their functions were discovered through this system such as avrRps 4 corresponding to RPS4 (Hinsch and Staskawicz 1996) and RPS6 in Arabidopsis resistant to effector HopA1 of $P$. syringae (Kim et al. 2009). Also, effector proteins ATR1 and ATR13 from $H$. parasitica were found to enhance susceptibility of Arabidopsis to P. syringae and both of them stimulated growth of the bacteria in Arabidopsis leaves (Sohn et al. 2007), which were findings similar to the data of Cri-9402 (Fig. 3C). These results indicated that the Arabidopsis $-P$. syringae pathosystem was an efficient model to research interaction between plants and pathogens through either stable transformation or transient expression, both of which were reliable and repeatable. In this system, $P$. syringae is infiltrated by syringe injection, vacuum infiltration, or some surfactants to facilitate entry of the bacteria into intercellular space. However, this model is not suitable to research epiphytic interaction between hosts and pathogens. One reason is that artificially modified $P$. syringae does not grow well on the surface of plants (Katagiri et al. 2002).

Another interesting finding was that Cri-9402 caused opposite responses in tobacco and Arabidopsis leaves. It inhibited expression of several resistance-related genes in leaves of transformed Arabidopsis (Fig. 5) but upregulated expression of another set of resistance-related genes in tobacco leaves (Fig. 4). This effector stimulated growth of $P$. syringae Psm ES4326 in leaves of transformed Arabidopsis compared with the control but it suppressed the bacterial growth relatively in tobacco leaves with transient expression. Furthermore, in the transformed Arabidopsis leaves, Cri-9402 inhibited expression of several genes but it enhanced expression of $P D F 1.2$, an antifungal peptide in Arabidopsis (Thomma et al. 2002). Even though PDF1.2 had

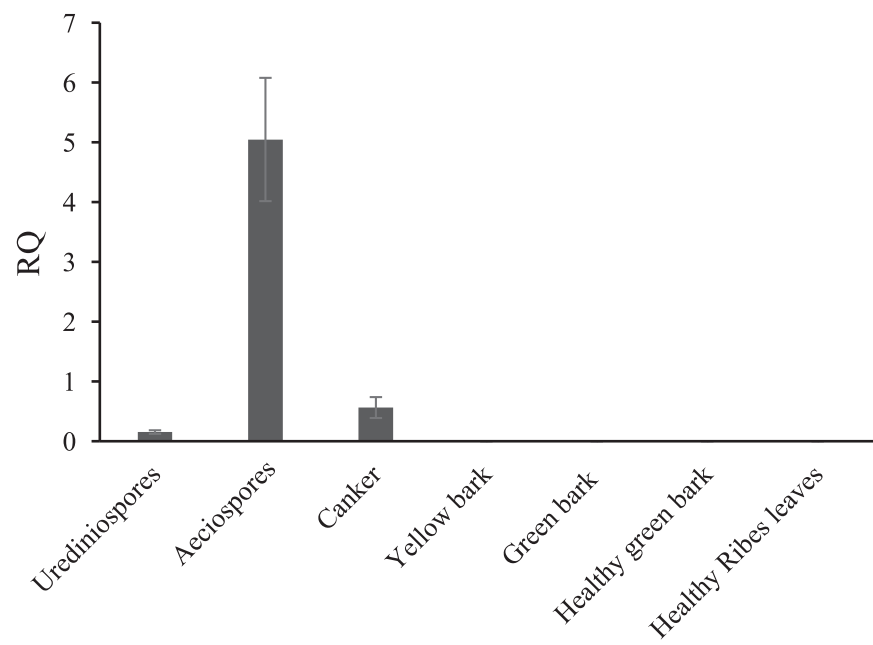

Fig. 6. Real-time polymerase chain reaction analysis of Cri-9402 transcript expression. Urediniospores were collected from surface of infected Ribes leaves. Aeciospores were collected from infected bark of western white pine. Canker, yellow bark, and green bark next to the yellow infected bark area were collected from 5-year-old western white pine seedlings. Healthy green bark from 5-year-old western white pine seedlings and healthy Ribes leaves, both without rust infection, were collected as negative controls. RQ = relative quantification as calculated by $2^{-\Delta \Delta C t}$. 
significantly higher expression (Fig. 5), it did not inhibit growth of P. syringae Psm ES4326 in the transformed Arabidopsis leaves compared with control seedlings. It awaits future studies to fully understand what caused the symptoms observed in the present study.

Our results showed that effector Cri-9402 inhibited or enhanced growth of $P$. syringae Psm ES4326, incidentally regulating host defense response differentially in distinct host plants (Fig. 4). These results suggest that this effector may be a component manipulating tree defense during $C$. ribicola-white pine interactions. The Cri9402 transcript had a much higher expression level in aeciospores than in urediniospores, indicating that it played a more important role in aeciospores. Its expression was undetectable in yellow bark and the green bark tissue next to the infected area of the cankered western white pine seedlings (Fig. 6), suggesting that it might have no or extremely low expression in hyphae of the tested $C$. ribicola phylotypes. It was expressed in canker tissue (Fig. 6) but it was difficult to make a clear conclusion about its role in hyphal growth and infection because both aeciospores and hyphae of $C$. ribicola were present in the cankered bark tissues. To summarize the above data, Cri-9402 probably played an important role in production or germination of aeciospores of $C$. ribicola.

$\mathrm{R}$ candidates for MGRs against $C$. ribicola have been reported in several five-needle pine species (Liu et al. 2017, 2019b; Stevens et al. 2016). If molecular interactions between these host $\mathrm{R}$ candidates and Cri-9402 or other $C$. ribicola candidate effectors could be confirmed in the WPBR pathosystems, roles of $C$. ribicola effectors would be more convincing, providing additional approaches to explore novel $R$ genes in western white pine and other five-needle pine species.

\section{ACKNOWLEDGMENTS}

We thank G. Roke and H. Williams at the Canadian Forest Service for sample collection and critical review of the manuscript.

\section{LITERATURE CITED}

Anderson, J. P. 2004. Antagonistic interaction between abscisic acid and jasmonate-ethylene signaling pathways modulates defense gene expression and disease resistance in Arabidopsis. Plant Cell 16:3460-3479.

Asai, S., Rallapalli, G., Piquerez, S. J. M., Caillaud, M.-C., Furzer, O. J., Ishaque, N., Wirthmueller, L., Fabro, G., Shirasu, K., and Jones, J. D. G. 2014. Expression profiling during Arabidopsis/downy mildew interaction reveals a highly-expressed effector that attenuates responses to salicylic acid. PLoS Pathog. 10:e1004443.

Bernard, P. 1996. Positive selection of recombinant DNA by $c c D B$. Biotechniques 21:320-323.

Bhadauria, V., Banniza, S., Vandenberg, A., Selvaraj, G., and Wei, Y. 2013. Overexpression of a novel biotrophy-specific Colletotrichum truncatum effector, CtNUDIX, in hemibiotrophic fungal phytopathogens causes incompatibility with their host plants. Eukaryot. Cell 12:2-11.

Buyel, J. F., Buyel, J. J., Haase, C., and Fischer, R. 2015. The impact of Pseudomonas syringae type III effectors on transient protein expression in tobacco. Plant Biol. (Berlin, Ger.) 17:484-492.

Caillaud, M.-C., Asai, S., Rallapalli, G., Piquerez, S., Fabro, G., and Jones, J. D. G. 2013. A downy mildew effector attenuates salicylic acid-triggered immunity in Arabidopsis by interacting with the host mediator complex. PLoS Biol. 11:e1001732.

Catanzariti, A.-M. 2006. Haustorially expressed secreted proteins from flax rust are highly enriched for avirulence elicitors. Plant Cell 18:243-256.

Chiang, Y.-H., and Coaker, G. 2015. Effector triggered immunity: NLR immune perception and downstream defense responses. Arabidopsis Book 13:e0183.

Clough, S. J., and Bent, A. F. 1998. Floral dip: A simplified method for Agrobacterium-mediated transformation of Arabidopsis thaliana. Plant J. 16:735-743.

Czernic, P., Chen Huang, H., and Marco, Y. 1996. Characterization of hsr201 and $h s r 515$, two tobacco genes preferentially expressed during the hypersensitive reaction provoked by phytopathogenic bacteria. Plant Mol. Biol. 31:255-265

Deng, W.-L., Lin, Y. C., Lin, R.-H., Wei, C.-F., Huang, Y.-C., Peng, H.-L., and Huang, H.-C. 2010. Effects of galU mutation on Pseudomonas syringaeplant interactions. Mol. Plant-Microbe Interact. 23:1184-1196.
Ding, Y., Sun, T., Ao, K., Peng, Y., Zhang, Y., Li, X., and Zhang, Y. 2018. Opposite roles of salicylic acid receptors NPR1 and NPR3/NPR4 in transcriptional regulation of plant immunity. Cell 173:1454-1467.E15.

Dodds, P. N. 2004. The Melampsora lini AvrL567 Avirulence genes are expressed in haustoria and their products are recognized inside plant cells. Plant Cell 16:755-768.

Dodds, P. N., and Rathjen, J. P. 2010. Plant immunity: Towards an integrated view of plant-pathogen interactions. Nat. Rev. Genet. 11:539-548.

Germain, H., Joly, D. L., Mireault, C., Plourde, M. B., Letanneur, C., Stewart, D., Morency, M. J., Petre, B., Duplessis, S., and Séguin, A. 2018. Infection assays in Arabidopsis reveal candidate effectors from the poplar rust fungus that promote susceptibility to bacteria and oomycete pathogens. Mol. Plant Pathol. 19:191-200.

Godfrey, D., Böhlenius, H., Pedersen, C., Zhang, Z., Emmersen, J., and Thordal-Christensen, H. 2010. Powdery mildew fungal effector candidates share N-terminal Y/F/WxC-motif. BMC Genomics 11:317.

Grimsley, N., Hohn, B., Hohn, T., and Walden, R. 1986. "Agroinfection," an alternative route for viral infection of plants by using the Ti plasmid. Proc. Natl. Acad. Sci. U.S.A. 83:3282-3286.

Gupta, P., Ravi, I., and Sharma, V. 2013. Induction of $\beta$-1,3-glucanase and chitinase activity in the defense response of Eruca sativa plants against the fungal pathogen Alternaria brassicicola. J. Plant Interact. 8:155-161.

Hinsch, M., and Staskawicz, B. 1996. Identification of a new Arabidopsis disease resistance locus, RPs4, and cloning of the corresponding avirulence gene, avrRps4, from Pseudomonas syringae pv. pisi. Mol. Plant-Microbe Interact. 9:55-61.

Hogenhout, S. A., Van der Hoorn, R. A. L., Terauchi, R., and Kamoun, S. 2009. Emerging concepts in effector biology of plant-associated organisms. Mol. Plant-Microbe Interact. 22:115-122.

Iakovidis, M., Teixeira, P. J., Exposito-Alonso, M., Cowper, M. G., Law, T. F., Liu, Q., Vu, M. C., Dang, T. M., Corwin, J. A., Weigel, D., Dangl, J. L., and Grant, S. R. 2016. Effector-triggered immune response in Arabidopsis thaliana is a quantitative trait. Genetics 204:337-353.

Juge, N. 2006. Plant protein inhibitors of cell wall degrading enzymes. Trends Plant Sci. 11:359-367.

Kale, S. D., Gu, B., Capelluto, D. G., Dou, D., Feldman, E., Rumore, A., Arredondo, F. D., Hanlon, R., Fudal, I., Rouxel, T., Lawrence, C. B., Shan, W., and Tyler, B. M. 2010. External lipid PI3P mediates entry of eukaryotic pathogen effectors into plant and animal host cells. Cell 142:284-295.

Karimi, M., Inzé, D., and Depicker, A. 2002. GATEWAY vectors for Agrobacterium-mediated plant transformation. Trends Plant Sci. 7:193-195.

Katagiri, F., Thilmony, R., and He, S. Y. 2002. The Arabidopsis thalianaPseudomonas syringae interaction. Arabidopsis Book 1:e0039.

Katsir, L., Schilmiller, A. L., Staswick, P. E., He, S. Y., and Howe, G. A. 2008. COI1 is a critical component of a receptor for jasmonate and the bacterial virulence factor coronatine. Proc. Natl. Acad. Sci. U.S.A. 105: 7100-7105.

Kemen, E., Kemen, A. C., Rafiqi, M., Hempel, U., Mendgen, K., Hahn, M., and Voegele, R. T. 2005. Identification of a protein from rust fungi transferred from haustoria into infected plant cells. Mol. Plant-Microbe Interact. 18:1130-1139.

Kim, S. H., Kwon, S. I., Saha, D., Anyanwu, N. C., and Gassmann, W. 2009. Resistance to the Pseudomonas syringae effector HopA1 is governed by the TIR-NBS-LRR protein RPS6 and is enhanced by mutations in SRFR1. Plant Physiol. 150:1723-1732.

Kinloch, B. B., Sniezko, R. A., Barnes, G. D., and Greathouse, T. E. 1999. A major gene for resistance to white pine blister rust in western white pine from the Western cascade range. Phytopathology 89:861-867.

Kinloch, B. B., Jr., Sniezko, R. A., and Dupper, G. E. 2003. Origin and distribution of $\mathrm{Cr} 2$, a gene for resistance to white pine blister rust in natural populations of western white pine. Phytopathology 93:691-694.

Kushalappa, A. C., Yogendra, K. N., and Karre, S. 2016. Plant innate immune response: Qualitative and quantitative resistance. Crit. Rev. Plant Sci. 35: 38-55.

Lee, H.-R., Lee, S., Park, S., Kleeff, P. J. M., van Schuurink, R. C., and Ryu, C.-M. 2018. Transient expression of whitefly effectors in Nicotiana benthamiana leaves activates systemic immunity against the leaf pathogen Pseudomonas syringae and soil-borne pathogen Ralstonia solanacearum. Front. Ecol. Evol. 6:90.

Levy, M., Rachmilevitch, S., and Abel, S. 2005. Transient Agrobacteriummediated gene expression in the Arabidopsis hydroponics root system for subcellular localization studies. Plant Mol. Biol. Report. 23:179-184.

Liu, C., Pedersen, C., Schultz-Larsen, T., Aguilar, G. B., Madriz-Ordeñana, K., Hovmøller, M. S., and Thordal-Christensen, H. 2019a. The stripe rust fungal effector PEC6 suppresses pattern-triggered immunity in a host speciesindependent manner and interacts with adenosine kinases. New Phytol. 213: 1556.

Liu, J.-J., Schoettle, A. W., Sniezko, A. R., Yao, F., Zamany, A., Williams, H., and Rancourt, B. 2019b. Limber pine (Pinus flexilis James) genetic map 
constructed by exome-seq provides insight into evolution of disease resistance and a genomic resource for genomics-based breeding. Plant J. doi: $10.1111 /$ tpj. 14270

Liu, J.-J., Sniezko, R. A., Zamany, A., Williams, H., Wang, N., Kegley, A., Savin, D. P., Chen, H., and Sturrock, R. N. 2017. Saturated genic SNP mapping identified functional candidates and selection tools for the Pinus monticola $\mathrm{Cr} 2$ locus controlling resistance to white pine blister rust. Plant Biotechnol. J. 15:1149-1162.

Liu, J.-J., Sturrock, R. N., Sniezko, R. A., Williams, H., Benton, R., and Zamany, A. 2015. Transcriptome analysis of the white pine blister rust pathogen Cronartium ribicola: De novo assembly, expression profiling, and identification of candidate effectors. BMC Genomics 16:678.

Lorenzo, O., Piqueras, R., Sánchez-Serrano, J. J., and Solano, R. 2003. ETHYLENE RESPONSE FACTOR1 integrates signals from ethylene and jasmonate pathways in plant defense. Plant Cell 15:165-178.

Ma, L., Lukasik, E., Gawehns, F., and Takken, F. L. W. 2012. The use of agroinfiltration for transient expression of plant resistance and fungal effector proteins in Nicotiana benthamiana leaves. Methods Mol. Biol. 835:61-74.

Maloy, O. C. 2003 (updated 2018). White pine blister rust. Plant Health Instruct. doi.org/10.1094/PHI-I-2003-0908-01

Mueller, A. N., Ziemann, S., Treitschke, S., Aßmann, D., and Doehlemann, G. 2013. Compatibility in the Ustilago maydis-maize interaction requires inhibition of host cysteine proteases by the fungal effector Pit2. PLoS Pathog. 9:e1003177.

Nirmala, J., Drader, T., Lawrence, P. K., Yin, C., Hulbert, S., Steber, C. M., Steffenson, B. J., Szabo, L. J., von Wettstein, D., and Kleinhofs, A. 2011. Concerted action of two avirulent spore effectors activates reaction to Puccinia graminis1 (Rpg1)-mediated cereal stem rust resistance. Proc. Natl. Acad. Sci. U.S.A. 108:14676-14681.

Penninckx, I. A., Eggermont, K., Terras, F. R., Thomma, B. P., De Samblanx, G. W., Buchala, A., Métraux, J. P., Manners, J. M., and Broekaert, W. F. 1996. Pathogen-induced systemic activation of a plant defensin gene in Arabidopsis follows a salicylic acid-independent pathway. Plant Cell 8: 2309-2323.

Persoons, A., Morin, E., Christine, D., Payen, T., Halkett, F., Frey, P., De Mita, S., and Duplessis, S. 2014. Patterns of genomic variation in the poplar rust fungus Melampsora larici-populina identify pathogenesis-related factors. Front. Plant Sci. 5:450.

Petre, B., Joly, D. L., and Duplessis, S. 2014. Effector proteins of rust fungi. Front. Plant Sci. 5:416.

Petre, B., Saunders, D. G. O., Sklenar, J., Lorrain, C., Win, J., Duplessis, S., and Kamoun, S. 2015. Candidate effector proteins of the rust pathogen Melampsora larici-populina target diverse plant cell compartments. Mol. Plant-Microbe Interact. 28:689-700.

Pontier, D., Godiard, L., Marco, Y., and Roby, D. 1994. hsr203J, a tobacco gene whose activation is rapid, highly localized and specific for incompatible plant/pathogen interactions. Plant J. 5:507-521.

Pretsch, K., Kemen, A., Kemen, E., Geiger, M., Mendgen, K., and Voegele, R. 2013. The rust transferred proteins-a new family of effector proteins exhibiting protease inhibitor function. Mol. Plant Pathol. 14:96-107

Raffaello, T., and Asiegbu, F. O. 2017. Small secreted proteins from the necrotrophic conifer pathogen Heterobasidion annosum s.l. (HaSSPs) induce cell death in Nicotiana benthamiana. Sci. Rep. 7: Article 8000.

Rafiqi, M., Ellis, J. G., Ludowici, V. A., Hardham, A. R., and Dodds, P. N. 2012. Challenges and progress towards understanding the role of effectors in plant-fungal interactions. Curr. Opin. Plant Biol. 15:477-482.

Rafiqi, M., Gan, P. H. P., Ravensdale, M., Lawrence, G. J., Ellis, J. G., Jones, D. A., Hardham, A. R., and Dodds, P. N. 2010. Internalization of flax rust avirulence proteins into flax and tobacco cells can occur in the absence of the pathogen. Plant Cell 22:2017-2032.

Selin, C., Kievit, T. R., de Belmonte, M. F., and Fernando, W. G. D. 2016. Elucidating the role of effectors in plant-fungal interactions: Progress and challenges. Front. Microbiol. 7:600.

Sinha, M., Singh, R. P., Kushwaha, G. S., Iqbal, N., Singh, A., Kaushik, S., Kaur, P., Sharma, S., and Singh, T. P. 2014. Current overview of allergens of plant pathogenesis related protein families. Sci. World J. 2014: Article 543195

Sniezko, R., Smith, J., Liu, J.-J., and Hamelin, R. 2014. Genetic resistance to fusiform rust in southern pines and white pine blister rust in five-needle pines-A contrasting tale of two rust pathosystems-Current status and future prospects. Forests 5:2050-2083.
Sohn, K. H., Lei, R., Nemri, A., and Jones, J. D. G. 2007. The downy mildew effector proteins ATR1 and ATR13 promote disease susceptibility in Arabidopsis thaliana. Plant Cell 19:4077-4090.

Sperschneider, J., Dodds, P. N., Gardiner, D. M., Manners, J. M., Singh, K. B., and Taylor, J. M. 2015. Advances and challenges in computational prediction of effectors from plant pathogenic fungi. PLoS Pathog. 11: e1004806.

Sperschneider, J., Ying, H., Dodds, P. N., Gardiner, D. M., Upadhyaya, N. M., Singh, K. B., Manners, J. M., and Taylor, J. M. 2014. Diversifying selection in the wheat stem rust fungus acts predominantly on pathogen-associated gene families and reveals candidate effectors. Front. Plant Sci. 5:372.

Stevens, K. A., Wegrzyn, J. L., Zimin, A., Puiu, D., Crepeau, M., Cardeno, C., Paul, R., Gonzalez-Ibeas, D., Koriabine, M., and Holtz-Morris, A. E. 2016. Sequence of the sugar pine megagenome. Genetics 204:1613-1626.

Stotz, H. U., Mitrousia, G. K., de Wit, P. J. G. M., and Fitt, B. D. L. 2014. Effector-triggered defence against apoplastic fungal pathogens. Trends Plant Sci. 19:491-500.

Thomma, B., Cammue, B., and Thevissen, K. 2002. Plant defensins. Planta 216:193-202.

Upadhyaya, N. M., Mago, R., Staskawicz, B. J., Ayliffe, M. A., Ellis, J. G., and Dodds, P. N. 2014. A bacterial type III secretion assay for delivery of fungal effector proteins into wheat. Mol. Plant-Microbe Interact. 27:255-264

van Verk, M. C., Pappaioannou, D., Neeleman, L., Bol, J. F., and Linthorst, H. J. 2008. A novel WRKY transcription factor is required for induction of $P R-1 a$ gene expression by salicylic acid and bacterial elicitors. Plant Physiol. 146:1983-1995.

Ve, T., Williams, S. J., Catanzariti, A. M., Rafiqi, M., Rahman, M., Ellis, J. G., Hardham, A. R., Jones, D. A., Anderson, P. A., Dodds, P. N., and Kobe, B. 2013. Structures of the flax-rust effector AvrM reveal insights into the molecular basis of plant-cell entry and effector-triggered immunity. Proc. Natl. Acad. Sci. U.S.A. 110:17594-17599.

Venugopal, S. C., Jeong, R. D., Mandal, M. K., Zhu, S., Chandra-Shekara, A. C., Xia, Y., Hersh, M., Stromberg, A. J., Navarre, D., Kachroo, A., and Kachroo, P. 2009. Enhanced disease susceptibility 1 and salicylic acid act redundantly to regulate resistance gene-mediated signaling. PLoS Genet. 5:e1000545.

Vijayan, P., Shockey, J., Lévesque, C. A., Cook, R. J., and Browse, J. 1998. A role for jasmonate in pathogen defense of Arabidopsis. Proc. Natl. Acad. Sci. U.S.A. 95:7209-7214.

Vleeshouwers, V. G. A. A., and Oliver, R. P. 2014. Effectors as tools in disease resistance breeding against biotrophic, hemibiotrophic, and necrotrophic plant pathogens. Mol. Plant-Microbe Interact. 27:196-206.

Vogan, P. J., and Schoettle, A. W. 2015. Selection for resistance to white pine blister rust affects the abiotic stress tolerances of limber pine. For. Ecol. Manage. 344:110-119.

Wang, C., Gao, F., Wu, J., Dai, J., Wei, C., and Li, Y. 2010. Arabidopsis putative deacetylase AtSRT2 regulates basal defense by suppressing PAD4, EDS5 and SID2 expression. Plant Cell Physiol. 51:1291-1299.

Wildermuth, M. C., Dewdney, J., Wu, G., and Ausubel, F. M. 2001. Isochorismate synthase is required to synthesize salicylic acid for plant defence. Nature 414:562-565.

Win, J., Morgan, W., Bos, J., Krasileva, K. V., Cano, L. M., Chaparro-Garcia, A., Ammar, R., Staskawicz, B. J., and Kamoun, S. 2007. Adaptive evolution has targeted the C-terminal domain of the RXLR effectors of plant pathogenic Oomycetes. Plant Cell 19:2349-2369.

Wroblewski, T., Tomczak, A., and Michelmore, R. 2005. Optimization of Agrobacterium-mediated transient assays of gene expression in lettuce, tomato and Arabidopsis. Plant Biotechnol. J. 3:259-273.

Yan, J., Zhang, C., Gu, M., Bai, Z., Zhang, W., Qi, T., Cheng, Z., Peng, W., Luo, H., Nan, F., Wang, Z., and Xie, D. 2009. The Arabidopsis CORONATINE INSENSITIVE1 protein is a jasmonate receptor. Plant Cell 21: 2220-2236.

Yang, Y., Li, R., and Qi, M. 2000. In vivo analysis of plant promoters and transcription factors by agroinfiltration of tobacco leaves. Plant J. 22: 543-551.

Yu, D., Chen, C., and Chen, Z. 2001. Evidence for an important role of WRKY DNA binding proteins in the regulation of NPRl gene expression. Plant Cell 13:1527-1540.

Zhang, M., Rajput, N. A., Shen, D., Sun, P., Zeng, W., Liu, T., Mafurah, J. J., and Dou, D. 2015. A Phytophthora sojae cytoplasmic effector mediates disease resistance and abiotic stress tolerance in Nicotiana benthamiana. Sci. Rep. 5: Article 10837. 